\title{
ARTIGO CIENTÍFICO: DAS PRIMEIRAS CARTAS AO GÊNERO DIGITAL
}

\author{
SCIENTIFIC PAPER: FROM THE FIRST LETTERS TO DIGITAL GENRE
}

\section{Viviane Raposo Pimenta}

UFU / UFOP

\begin{abstract}
RESUMO: Com o advento das tecnologias digitais da informação e comunição (TDICS) surgem novas possibilidades de fazer sentido como forma de resposta às demandas sociais que envolvem a utilização dos recursos tecnológicos no meio digital, e, assim, construir sentido a partir de textos multimodais e multissemióticos que mesclam palavras, elementos pictóricos, sonoros, imagens estáticas e em movimento, numa mesma superfície. Trata-se de criar um ambiente mais sintonizado com a modalidade comunicacional digital emergente. No entanto, embora inúmeros pesquisadores da área da Linguística e da Linguística Aplicada já estejam desenvolvendo pesquisas e defendam a utilização das TDICS e a promoção dos multiletramentos, o gênero 'artigo científico' não sofreu mudanças significativas haja vista que mesmo os textos escritos para o ambiente digital não se utilizam das inúmeras possibilidades que esse suporte oferece aos seus produtores. Assim, embora as TDICS nos ofereçam possibilidades de produção criativa de hipertextos interativos e, mais que isto, cooperativos, textos multimodais que possam levar o seu interlocutor para um cenário de navegação fluído e dinâmico, os periódicos de divulgação científica, já na segunda década do século XXI, têm se posicionado como 'guardiões da tradição' e requerem de seus colaboradores a produção de textos lineares mantendo sua estrutura inalterada.
\end{abstract}

PALAVRAS-CHAVE: artigo científico, estrutura composicional, tecnologias digitais da informação e comunicação (TDICS); periódicos de divulgação científica; gênero digital.

\begin{abstract}
With the advent of digital technologies of information and communication (TDICS) new possibilities to make sense as a response to social demands involving the use of technological resources in the digital environment arise, and thus meaning making from multimodal multisemiotic texts that mix words, pictorial elements, sound, still and moving pictures, on the same surface. It is about creating an environment more in tune with the emerging digital communication mode. However, although many researchers in the field of Linguistics and Applied Linguistics have already been conducting research and defend the use of TDICS and the promotion of multiliteracies, the genre 'scientific paper' has not undergone significant changes once even the texts written for the digital environment do not use the various possibilities the digital midia offers to support its producers. Thus, although TDICS offer possibilities for the creative production of interactive hypertext and more than that, cooperative multimodal texts that can take your partner to a fluid and dynamic scenario of navigation, the scientific journals, in the second decade of the twenty-first century, have positioned themselves as "guardians of tradition" and require from its colaborators to produce linear texts, keeping its structure practically unchanged.
\end{abstract}

KEYWORDS: scientific paper; compositional structure; digital technologies of information and communication; scientific journals; digital genre. 


\section{Revista do SELL \\ v. $4, n^{\circ} .1$ \\ ISSN: $1983-3873$}

\section{INTRODUÇÃO}

Os primeiros periódicos voltados para a divulgação científica datam do século XVII, essas publicações formalizaram os artigos científicos como forma de comunicação e troca entre pesquisadores localizados em diferentes lugares e períodos históricos. Com a evolução e o surgimento de novas tecnologias, esta forma de comunicação foi se aprimorando e continua sendo o meio mais utilizado pelos pesquisadores para divulgação de suas pesquisas científicas uma vez que trata-se de uma ferramenta rápida, econômica e de fácil divulgação.

Com o advento das tecnologias digitais de comunicação e informação - TDICS os pesquisadores passaram a contar com ferramentas que lhes permitem a utilização de uma infinidade de modalidades de linguagens e assim produzirem textos muito mais atraentes, interativos e colaborativos. No entanto, essas tecnologias digitais são subutilizadas pelos cientistas, pois seu comportamento em relação aos periódicos eletrônicos parece estar muito próximo da forma com que sempre utilizaram os periódicos impressos.

Ora, se as TDICS podem ampliar e agilizar as possibilidades de comunicação entre os pesquisadores haja vista que o método analógico pode ser aprimorado e mimetizado digitalmente, o que nos permite dizer que complementam e até obrigam a evolução das metodologias consolidadas, resta-nos questionar por que o artigo científico - considerado uma das bases da divulgação científica - continua apresentando uma estrutura linear quase que inalterada?

Para apresentar este estudo, faz-se, na primeira parte deste texto, um relato sobre o surgimento das tecnologias e como elas foram aceitas e sendo incorporadas ao nosso cotidiano e como a comunicação e informação tornou-se cada vez mais acessível e rápida. Em seguida, alguns dados sobre a história das formas de divulgação científica são apresentados no sentido de melhor compreender a estrutura do artigo científico que é discutida na parte seguinte.

Observa-se que, não obstante as várias revisões formais quanto à estrutura do artigo científico, este mantém até os dias atuais uma estrutura fixa que, em linhas gerais, apresenta um panorama geral dos avanços científicos daquela área de estudo e pesquisa, uma revisão dos principais marcos teóricos para dar suporte teórico ao estudo, uma breve descrição da metodologia utilizada na pesquisa que está sendo apresentada, uma discussão sobre os dados apresentados no estudo, e uma pequena síntese 


\section{Revista do SELL}

v. $4, n^{\circ} .1$

ISSN: $1983-3873$

apresentada ao final que sistematiza as novas descobertas e abre espaço para novos estudos.

Nota-se que a estrutura do texto embora possa, por vezes, apresentar algumas figuras, quadros e tabelas para complementar os sentidos das palavras, permanece totalmente linear, o que nos possibilita dizer que mesmo sendo escrito para o meio digital, o texto possui uma formatação e estruturação voltada para a publicação no meio impresso, ou seja, não se utiliza das características que o meio digital thes possibilita como a hipermídia e os hiperlinks que poderiam dar ao texto uma variedade enorme de possibilidades de novas abordagens na construção dos conteúdos.

Neste sentido, pode-se questionar a relação dos escritores e leitores dos artigos de divulgação científica com as TDICS e o seu uso na produção da escrita e leitura não linear e desestruturada.

\section{Das primeiras tecnologias às tecnologias digitais da comunicação e informação}

É fato que, ao longo da História, as comunidades sempre sentiram a necessidade de usar recursos externos para ampliar as possibilidades de trocas de informação. Somos seres sociais e precisamos da linguagem para interações que viabilizam trocas que são essenciais para a construção, manutenção e evolução das culturas comunitárias. Muitos desses recursos hoje são tão antigos que já ficaram quase tão "naturais" quanto a fala.

No mundo acadêmico, não há quem pense na possibilidade da construção dos saberes sem usar a escrita. No entanto, sabemos que nem sempre foi assim, pois os gregos na Antiguidade, por exemplo, discutiam se a leitura de textos escritos poderia ser uma fonte de aprendizado. Para Sócrates - para quem o ensino era centrado na conversa entre discípulos e mestre -, depender da escrita iria prejudicar a memória (pois os textos eram memorizados) e ler o texto na ausência do seu autor só iria favorecer interpretações erradas. Para o filósofo a escrita era um problema para a educação e não uma fonte de apoio. Isso parece estranho na realidade de hoje, na qual o texto escrito é uma ferramenta fundamental para nossas práticas acadêmicas. Na realidade, a escrita é tão "natural" que, muitas vezes, até não nos damos conta de que o texto escrito - impresso ou não - é um produto da tecnologia. Devido a essa naturalização do texto escrito, muitos acadêmicos se esquecem de sua fonte - o texto oral - e o têm como única fonte legitima de transmissão do conhecimento. Efeito Sócrates "de ponta cabeça". 


\section{Revista do SELL \\ v. $4, n^{\circ} .1$ \\ ISSN: $1983-3873$}

Para Buzato (2011), se voltarmos na História, é fácil entender os temores de Sócrates e ver como eles encontram paralelos nos dias atuais. Na época desse filósofo os gregos já tinham desenvolvido a escrita, mas a produção de textos escritos era relativamente pequena, dada a dificuldade e custo do papiro e de pergaminhos e a consulta desses textos também era complicada. Os rolos eram tiras enormes de papéis (papiros e pergaminhos) e, a medida em que uma mão desenrolava uma parte, a outra tinha que enrolar a parte oposta. Não dava para ler e tomar notas como fazemos hoje. Logo, era mais simples e eficiente "decorar" os textos. Hoje usamos nossa memória de uma forma mais eficiente, que envolve processos complexos de consulta a diferentes textos orais e escritos. Nesse processo de construção do conhecimento, usamos também notas manuscritas - resultado de retextualizações - ou digitalizadas como estratégias de estudo. A naturalização da escrita nas práticas acadêmicas nos leva a estranhar as críticas feitas por Sócrates. No entanto, não estranhamos tanto quando as pessoas acreditam que o uso de máquinas calculadoras fez com que as pessoas mais jovens perdessem a capacidade de fazer "contas de cabeça". Como a máquina realiza operações numéricas de forma ágil e confiável, certos tipos de conhecimentos que antes precisavam ser memorizados, hoje são realizados de outra forma. Isso permite que, em princípio, nossos recursos de memória sejam explorados para operações mais complexas.

É possível que, no futuro, lendo sobre as críticas feitas hoje às calculadoras, as pessoas sintam o mesmo estranhamento que sentimos ao ler as colocações feitas por Sócrates ao texto escrito, e, no entanto, sem o registro escrito, hoje não teríamos condições de ter acesso e refletir sobre as colocações de Sócrates feitas em um período tão distante na história (Buzato, 2011).

Trazendo esse problema para a realidade mais atual, hoje ainda há pessoas que avaliam os recursos oferecidos pelo computador e pela Internet com a mesma preocupação e suspeita que os gregos clássicos tinham sobre o texto escrito. Cabe avaliarmos essa questão, entendendo de forma mais esclarecida as possibilidades que a tecnologia digital traz para as práticas comunicativas que fazem parte do nosso cotidiano atual.

Buzato (2011) fez um estudo detalhado sobre como as tecnologias foram sendo incorporadas em nossas vidas ao longo da história da humanidade. Segundo o autor, os estudos históricos indicam que as primeiras expressões escritas e figurativas, como as registradas nas figuras rupestres, tinham inicialmente uma função mística. Mas, 


\section{Revista do SELL \\ v. $4, n^{\circ} .1$ \\ ISSN: $1983-3873$}

gradativamente, elas não só migraram para outros tipos de suporte textuais como também passaram a cumprir funções mais cotidianas, registrando, para consulta posterior, informações sobre as mais diversas atividades culturais e transações comerciais. Esse processo, mesmo em sua fase mais primitiva, foi fruto de tecnologia.

Antes de refletirmos sobre o percurso da história da escrita, seria interessante que recuperar na história de nossas vidas, como o acesso a diferentes suportes e ferramentas de escrita mudou ao longo de nossas vidas escolar e profissional. Alguns de nós, por exemplo, devem se lembrar da evolução da caneta tinteiro às canetas com carga plástica recarregável até às canetas esferográficas.

Podemos entender como as invenções que passaram a ser exploradas na produção da escrita afetam de forma bastante direta as práticas de letramento. Quando o tinteiro ficava externo à caneta só podíamos escrever em lugares específicos. Primeiro as canetas---tinteiro e depois as esferográficas nos permitiram transportar nossa "ferramenta" de escrita para todo o lugar. Hoje com telefones celulares não só escrevemos mensagens de qualquer lugar como também as enviamos em tempo real para variados destinatários. O uso do envio de texto pelo celular também tem nos forçado a ser mais sucintos em nossas mensagens.

Vale a pena avaliar o quanto a tecnologia da escrita já mudou, mesmo no tempo curto de nossas vidas.

Sempre que nos deparamos com novas tecnologias, sentimos um estranhamento inicial que dificulta o seu uso. Existem pessoas que hoje veem a tecnologia como "inimigos impostos", outras como aliados valiosos. É fato que, no início, o novo assusta e irrita. Não podemos realizar ações que antes fazíamos de forma automática e somos forçados a entender a lógica de interface, os comandos e nos familiarizarmos com novos tipos de práticas comunicativas. Foi assim com as secretárias eletrônicas e com os controles remotos, só para citar alguns exemplos.

Hoje, não imaginamos nossa vida sem esses recursos. Os que se familiarizaram com o uso do computador e da Internet logo descobriram que, uma vez dominados os recursos que essas tecnologias oferecem, eles podem contribuir muito para facilitar nossa vida pessoal e profissional. Perdemos o medo com o uso (que transforma o "novo" em "familiar") e passamos a explorar esses usos quando compreendemos a sua funcionalidade em nossas vidas.

A construção da cultura depende da comunicação e a fala e a linguagem gestual são as formas mais naturais de comunicação, já que sua produção e recepção, em 


\section{Revista do SELL \\ v. $4, n^{\circ} .1$ \\ ISSN: $1983-3873$}

condições normais, não dependem de recursos externos ao nosso organismo. Mas, à medida que os conhecimentos e valores culturais foram se ampliando ao longo da história das diferentes comunidades, os indivíduos passaram a sentir a necessidade de formas alternativas de usar a linguagem e de ampliar seu potencial de trocas comunicativas. Para isso, começaram a criar recursos materiais que permitissem o registro de informações ou mensagens (nas paredes das cavernas, nas placas de pedra, barro ou madeira, em pedaços de couro de animais ou, posteriormente, na manipulação de fibras de plantas usadas para fabricar os papiros). Gradativamente, foram também criando novas convenções de linguagem que permitiam a troca de mensagens, mesmo se as pessoas estivessem distantes. Sinais de fumaça, o som de batidas em árvores e tambores e o som de cornos de animais usados como trombetas foram, possivelmente, as formas mais primitivas de comunicação a distância criadas pelos seres humanos.

A tecnologia da imprensa ampliou e popularizou o acesso ao material escrito. No entanto, isso não resolveu o problema de comunicação a distância que as novas organizações sociais passaram a sentir necessidade. Esses problemas, aliados às possibilidades propiciadas pelas novas descobertas, como a eletricidade, foram o cerne do que hoje chamamos TDICS, ou seja, Tecnologias Digitais de Informação e Comunicação. Passamos por meios que permitiam acesso imediato a mensagens curtas, como os telégrafos, a formas que possibilitavam a transmissão e recepção de áudio, como o rádio, ou que abriram canais para a comunicação a distância, como o telefone. $\mathrm{O}$ registro de imagens também passou por mudanças significativas: fotografia em preto e branco, fotografia a cores, imagens em movimento exploradas pelo cinema, vídeo e programas da televisão. Surgiram as máquinas fotocopiadoras --- substituindo os antigos mimeógrafos --- e aparelhos de fax facilitaram a reprodução e envio de textos a pontos remotos.

A tecnologia digital, conforme Buzato (2007), permitiu que essas diferentes formas e possibilidades de construção de sentidos pudessem ser acessadas em uma única máquina: o computador. Com a Internet, na fase conhecida como Web 2.0, foi viabilizada a comunicação em tempo real ou quase real, que é central para a construção das redes sociais virtuais.

Esses diferentes recursos de acesso à informação e trocas interativas, antes dependentes de um computador fixo ligado à Internet, hoje tornaram---se móveis: aparelhos celulares, palms, tablets e laptops, por exemplo, fazem parte da tecnologia que 


\section{Revista do SELL}

v. $4, n^{\circ} .1$

ISSN: $1983-3873$

nos permite estar conectados nessa era em que a cultura torna---se simultaneamente local e global (Rojo, 2012; Buzato, 2007).

É importante lembrar como o uso de determinadas tecnologias sempre passa por um período inicial de familiarização e apropriação. Deve-se ressaltar que esse processo ocorre porque tais tecnologias tornam---se cada vez mais presentes em nossas vidas. Isso acontece porque um grande número de pessoas percebe que as inovações trazem facilidades para a realização de práticas já familiares ou dão origem a novas possibilidades de ações. Comumente, quando se fala em tecnologia e comunicação, logo nos vêm à mente os diferentes recursos oferecidos pelas TDICS. Como já foi dito, por estarmos tão familiarizados hoje com a escrita, é comum não lembrarmos que ela é também produto de uma tecnologia que se desenvolveu ao longo de milhares de anos. É por isto que refletir sobre o passado pode nos ajudar a pensar o presente.

Historicamente, segundo Buzato (2011), o desenvolvimento da tecnologia envolveu a escolha e criação de meios adequados para o registro do texto (tecnologia de suporte textual) e também instrumentos que permitiram realizar tais registros. Essa nova tecnologia foi gradativamente sendo aprimorada, de modo a facilitar a consulta e o transporte de material escrito. Basta compararmos os códex antigos, extremamente pesados, com os livros de bolso que temos hoje. Como era de se esperar, esses avanços na tecnologia de suporte, assim como o custo da reprodução de material escrito, também afetaram as situações e condições de leitura de texto.

Assim, os livros acabaram saindo dos sacrários e bibliotecas para nossas casas e foram incorporados também em nossas atividades de lazer. Além dessas mudanças na tecnologia de suporte, a popularização do uso da escrita também se deve às mudanças que ocorreram nas normas linguísticas, as quais foram adequando de forma cada vez mais eficiente a linguagem às possibilidades e limites dos novos meios de comunicação.

Ora a academia e os periódicos de divulgação científica não podem ficar alheios a essas mudanças tão significativas advindas com a globalização e o advento das TDICS.

Não podemos ignorar que:

Diferentemente das mídias anteriores (impressas e analógicas como a fotografia, o cinema, o rádio e a TV pré-digitais), a mídia digital, por sua própria natureza "tradutora" de outras linguagens para a linguagem dos dígitos binários e por sua concepção fundante em rede (web), permite que o usuário interaja em vários níveis e com vários interlocutores (interface, ferramentas, outros usuários, discursos etc.). Se as mídias anteriores eram destinadas à distribuição controlada da informação/comunicação - aliás, a imprensa se desenvolveu em grande parte com esse fim - , a ponto de se falar, no caso das mídias, que elas foram destinadas às massas (rádio, TV) em vez de às elites (imprensa, cinema) na constituição de uma "industria cultural" típica da modernidade, centralizada pelos interesses do capital e 


\section{Revista do SELL}

v. $4, n^{\circ} .1$

ISSN: $1983-3873$

das classes dominantes e que colocava o receptor no lugar de consumidor dos produtos culturais, a mídia digital e a digitalização (multi)mídia que a mesma veio a provocar mudou muito o panorama. (ROJO, 2012, p. 23)

$\mathrm{Na}$ atualidade, quando a complexidade da "cultura sensitiva" entra em ação, o visual, espacial, gestual, sonoro, imagético, pictórico, imagens estáticas e em movimento, a bricolagem são colocados em formas multimodais e multissemióticas de representação, pode-se dizer, então, que nem o mundo da representação poderia ser, em hipótese alguma, fixo (LEMKE, 1998).

Assim, o advento das TDICS parece envolver, a principio, um mero salto tecnológico que nos traz questões relacionadas aos meios de informação e formas de comunicação. De fato, os computadores estão, sem dúvidas, mudando o mundo, e as multimídias representam o topo da comunicação mediada por computadores e da tecnologia da informação. Conforme Kalantzis e Cope (2000), isto é o que todo um conjunto da literatura sobre o tema - desde escritos acadêmicos ultrapassados e escritos populares, assim como as novas formas de escrita publicadas na Internet - está nos dizendo na atualidade. De certa forma, esta é uma afirmação do óbvio. Como se sabe, as TDICS acabaram com o 'espaço' da forma como o conhecemos. Vivia-se em mundo cívico onde tinha-se que ir de um lugar para outro para realizar determinadas ações. $\mathrm{O}$ infobahn, ao contrário, é antiespacial. Coloca-se, assim, um final para as separações geográficas e institucionais. E, com o desaparecimento das 'distâncias', também as definições sociais de espaço perdem lugar. Na atualidade você pode morar em um lugar e trabalhar em outro muito distante, e a distinção entre "sua casa" e "o seu local de trabalho" se torna turva. Isto significa o fim das distinções sociais e "legibilidade cívica". A fachada do banco, o terno do seu chefe e a placa com letreiro na mesa ou na porta de um escritório, tudo ficou reduzido à igualdade de condições das páginas da Web e nas mensagens eletrônicas (emails), um tipo de república vernacular (Kalantzis e Cope, 2000).

Este ambiente das TDICS também é assíncrono, os corpos são 'avatares', um lugar de fácil anonimato e múltiplas identidades. A tendência tecnológica para a miniaturização, que está no cerne dessa revolução, pode eventualmente significar a desmaterialização, e caminhar em direção à comercialização de símbolos culturais, ao invés do comércio de coisas. Essas são algumas especulações atuais feitas por algumas correntes filosófico-tecnológicas presentes nas publicações científicas sobre os computadores, os sistemas de informação e os multimídias (Gilster, 1997; Mitchell, 1995). 


\section{Revista do SELL}

v. $4, n^{\circ} .1$

ISSN: $1983-3873$

\section{0 artigo científico: história e evolução}

Como descrito acima, a transição grega da oralidade para a escrita não aconteceu de um momento para outro. Os ensinamentos de Sócrates chegaram até nós por meio dos escritos do seu discípulo Platão. Assim, podemos dizer que, já a partir dos Diálogos Socráticos escritos por Platão, temos acesso aos conhecimentos filosóficos por meio da tecnologia da escrita.

No entanto, conforme Swales (1990), a comunicação entre os pesquisadores para transmitirem seus conhecimentos, pesquisas e descobertas científicas foi, inicialmente, realizada, no século XVII, por meio de cartas, o que possibilitou o diálogo e a apreciação crítica entre os cientistas. A correspondência pessoal tornou-se, pois, o meio utilizado pelos cientistas para a divulgação de suas ideias e estudos. Essas cartas eram trocadas entre amigos e ficavam restritas à apreciação de pequenos grupos, o que direcionava a sua divulgação, pois seus autores não as enviavam para pessoas que pudessem rejeitar suas teorias e experimentos. Assim, essas "dissertações epistolares", como as denominou McKie (1979), não poderiam ser consideradas como o método mais adequado para a divulgação de pesquisas e teorias científicas.

Foi, a partir dessas cartas informativas, afirma Swales (1990), que o artigo científico emergiu ainda de forma embrionária. Em 1965, surgem dois periódicos seminais com a proposta de possibilitar uma nova forma de comunicação das descobertas científicas, o Philosophical Transactions em Londres e o Journal dês Sçavants em Paris. O autor ressalta que, conforme Ard (1983), o gênero manteve, nos primeiros anos de sua existência neste novo suporte, várias características composicionais e de estilo apresentadas nas cartas pessoais, tais como a narrativa descritiva na primeira pessoa, algumas, inclusive, com a saudação "Sir" no seu início (SWALES, 1990, p. 110). No entanto, na medida em que o Transactions e outros periódicos foram se popularizando e assumiram o papel de principais meios de comunicação e discussão de textos acadêmicos, a nova situação retórica emergente levou à criação de um novo gênero muito distinto de sua origem composicional das cartas pessoais. Assim, os cientistas foram se familiarizando com essa nova forma de se comunicarem e adaptaram o formato de seus textos para esse novo suporte.

Como o Transactions era editado na Royal Society, uma sociedade científica com tradição nos estudos científicos, buscou-se estabelecer um formato próprio para as 


\section{Revista do SELL \\ v. $4, n^{\circ} .1$ \\ ISSN: $1983-3873$}

publicações relacionadas ao conhecimento científico, o que serviu de base para a criação dos periódicos científicos como os conhecemos. Já o caráter de disseminador de conteúdos variados na área das Ciências do Journal dês Sçavants pode ter, por seu caráter polissêmico, auxiliado a caracterizar as revistas modernas da área das humanidades.

Outra forma de registro das pesquisas realizadas no Século XVII eram as atas nas quais as descobertas que eram relatadas nas reuniões de uma sociedade científica eram transcritas e, posteriormente, impressas de forma resumida para que pudessem servir de fonte de consulta e referência aos membros das respectivas sociedades.

Assim, as cartas e atas eram utilizadas como veículos para a divulgação das descobertas individuais ou dos participantes de uma determinada sociedade, o que serviu de base para a criação das academias científicas e encontros de pesquisa. Era nesses encontros que os experimentos eram realizados e seus resultados discutidos e avaliados. Os resultados de pesquisa eram, então, registrados em cartas ou atas, que eram distribuídas aos pesquisadores que desenvolviam pesquisas similares. Com o aumento no número de sociedades e participantes dessas sociedades, seus membros acabavam por se dispersarem criando novas organizações mais estruturadas. Assim, as formas utilizadas para a divulgação de experimentos isolados acabaram por influenciar a criação das revistas que, com o passar do tempo, se tornaram as principais responsáveis pela divulgação das pesquisas, discussões e resultados científicos.

Percebe-se que os encontros entre cientistas da mesma área de atuação não deixaram de existir, ao contrário, as comunicações pessoais realizadas pelos cientistas passaram a ser registradas como anais desses eventos de divulgação científica nos quais são registrados e documentados os trabalhos apresentados nos encontros científicos.

Foi no século XIX que, com o aumento significativo do número de pesquisadores e pesquisas, as revistas científicas se popularizaram, além do fato de poderem, os pesquisadores, contar com as novas técnicas de impressão e produção do papel. Com a criação das revistas de resumos em 1830, o acesso às pesquisas acadêmicas tornou-se mais fácil. Já no século XX, com o fato das revistas serem publicadas por editores comerciais, pelas editoras universitárias e pelo Estado o crescimento das revistas de divulgação científica continuou bastante acentuado, e, a partir da década de 50, surgiram as publicações seriadas o que resultou num grande crescimento e na intensificação do controle bibliográfico. 


\section{Revista do SELL \\ v. $4, n^{\circ} .1$ \\ ISSN: $1983-3873$}

Ao longo dos anos, conforme Swales (1990), o formato das revistas, a estrutura composicional e o estilo do gênero de divulgação científica - artigo científico permaneceram quase que inalterados. Foi apenas com o avanço da tecnologia na década de 60 que surgiu o uso das microformas em substituição à cópia em papel, o que barateou o custo das assinaturas. No entanto, essa alternativa não foi bem aceita pelos assinantes nem pelas bibliotecas.

Nos anos 70, com o uso do computador, a editoração eletrônica avançou e permitiu a melhora e a rapidez na fase de editoração das revistas, o que foi prontamente aceito pelos leitores. No entanto, mesmo com o uso de disquetes e $C D-R O M$ o formato dos periódicos não chegou a ser modificado, mas propiciou acesso mais barato à informação e possibilitou o armazenamento de várias coleções em um pequeno espaço.

$\mathrm{Na}$ década de 90, surgem os periódicos disponíveis em rede, os artigos, já avaliados pelos pareceristas, são publicados em rede e podem ser acessados pelos leitores. Assim, as revistas eletrônicas desempenham bem a função de divulgação e democratização do acesso ao conhecimento.

Podemos dizer que desde então as tecnologias se desenvolveram enormemente e já contamos, há pelo menos duas décadas, com tecnologias digitais que possibilitam a produção de textos não lineares que podem apresentar links, vídeos, infográficos, elementos pictóricos e sonoros, imagens coloridas estáticas e em movimento. Também contamos com inúmeras pesquisas relacionadas ao uso das tecnologias digitais, aos multiletramentos, aos letramentos digitais, que, de uma forma ou de outra, promovem a discussão e a disseminação dos gêneros textuais digitais. No entanto, mesmo artigos de divulgação científica relacionados à promoção dos multiletramentos ainda não apresentam a multimodalidade e multissemiose características dos novos mídia digitais.

\section{Estrutura composicional e estilo do artigo científico}

Sabemos que as diferentes valorações das quais nos apropriamos acabam por derivar de diferentes enraizamentos socioculturais e de diferentes projetos de vida. Assim, em termos bakhtinianos, o aspecto mais importante do gênero é seu tema, que deriva de diferentes apreciações de valor. É ao tema que devemos reagir responsivamente. Estilo e forma de composição, na perspectiva de Bakhtin (1981, 1997), estão a serviço de fazer ecoar o tema. O tema depende da situação de produção, ou seja, dos propósitos de cada um para enunciar, da posição sócio-histórico-cultural-ideológica-epistemológica de cada 


\section{Revista do SELL}

v. $4, n^{\circ} .1$

ISSN: $1983-3873$

um. Se o estilo, as escolhas linguísticas que fazemos para dizer o que queremos dizer de léxico, sintaxe, registro etc. - para gerar o sentido desejado - e essas escolhas não são inocentes -, e a forma de composição, de organização e acabamento de todo o enunciado - (macro, super)estrutura do texto, progressão temática, de coerência e coesão que servem para marcar a fronteira do enunciado e passar a palavra ao outro são aspectos formais que estão a serviço de fazer ecoar o tema, se são marcas linguísticas das apreciações valorativas do autor, podemos dizer que na atualidade as interfaces multimidiáticas muito podem contribuir para que melhor possamos produzir sentidos a partir de textos multimodais.

Neste sentido, em relação à estrutura composicional e ao estilo dos artigos publicados em rede, conforme Meadows (1999), para que possamos analisá-los precisamos levar em consideração de que desde o século XVII esses estão em constante mudança para atenderem às solicitações dos editores, revisores e pareceristas dos atuais periódicos eletrônicos disponíveis em rede. No entanto, essas mudanças estão relacionadas à questões estruturais da escrita linear, pois, segundo o autor "muitas das mudanças por que têm passado [os elementos do artigo científico] estiveram relacionadas com o crescente aumento e complexidade da comunidade científica [...] e a necessidade de melhorar a eficiência de suas atividades de comunicação." (MEADOWS, 1999, p. 13).

Assim, podemos dizer que o artigo científico é estruturado de forma linear para atender aos propósitos comunicativos da comunidade discursiva, conforme Swales (1990) e Swales e Feak (1994), que requer que o texto, para ser aceito e publicado no periódico, mesmo os periódicos eletrônicos, apresente uma superestrutura linear, pois, conforme Aranha (2007, p. 10) "dela dependera ou não que o artigo seja aceito para a publicação pelos editores e também pela comunidade de leitores, além de poder ser citado por outros pesquisadores".

Para Swales (1990) a estrutura do artigo científico deve apresentar "IntroduçãoMétodo-Resultados-Discussão", o que o autor chama de (IMRD), conhecidos como os 4 movimentos retóricos. Já, para Marconi e Lakatos (1982), exige-se sempre a mesma estrutura nos artigos científicos: introdução, desenvolvimento e conclusão, que é basicamente a superestrutura de quase qualquer texto dissertativo. O uso dessa padronização, segundo os autores, ajuda em uma possível avaliação, pois o autor, ao utilizá-la, dá indícios de que teve um cuidado especial ao "construir" o texto e uma maior preocupação com o conteúdo. A superestrutura proposta por Van Djik (1987) também é baseada em uma estrutura textual linear, para o autor, o artigo científico deve apresentar 


\section{Revista do SELL \\ v. $4, n^{\circ} .1$ \\ ISSN: $1983-3873$}

minimamente as categorias: Resumo, no qual se faz uma breve exposição do texto e apenas os aspectos mais relevantes são apresentados - esta parte do artigo deve vir em Português e em uma língua estrangeira; Palavras-chave, com palavras específicas que têm o propósito de deixar claro o assunto tratado. Também deve vir em Português e em uma língua estrangeira; Introdução que refere-se à apresentação dos objetivos, do corpus, da metodologia, das hipóteses, das partes do texto e dos que trata cada uma; Desenvolvimento, que deve apresentar as análises, propostas e sustentação teórica; e Considerações Finais/ Conclusão, em que geralmente se faz um balanço do que foi conseguido e, em alguns casos, indicar a possibilidade de realização de futuros estudos.

As categorias apresentadas acima são, normalmente, as categorias mencionadas nos critérios para a avaliação dos artigos elaborados pelos editores dos periódicos científicos. No entanto, diante das mudanças ocorridas desde a invenção da escrita até o advento das tecnologias digitais da comunicação e informação, conforme Rojo (2009), podemos ressaltar pelo menos três mudanças que ganharam importância na reflexão sobre os processos de produção textual:

a) a intensificação vertiginosa e a diversificação da circulação da informação nos meios de comunicação analógicos e digitais, que, por isso mesmo, distanciam-se hoje dos meios impressos, muito mais morosos e seletivos, implicando, segundo alguns autores (CHARTIER, 1997; BEAUDOUIN, 2002), mudanças significativas nas maneiras de ler, de produzir e de fazer circular textos nas sociedades;

b) a diminuição das distâncias espaciais - tanto em termos geográficos, por efeito dos transportes rápidos, como em termos culturais e informacionais, por efeito da mídia digital, desenraizando as populações e desconstruindo identidades, e a diminuição das distâncias temporais ou a contração do tempo, determinadas pela velocidade sem precedentes, pela quase instantaneidade dos transportes, da informação, dos produtos culturais das mídias, características que também corroboram para mudanças nas práticas de letramentos;

c) a multissemiose que as possibilidades multimidiáticas e hipermidiáticas do texto eletrônico trazem para o ato de leitura: já não basta mais a leitura do texto verbal escrito - é preciso colocá-lo em relação com um conjunto de signos e de outras modalidades de linguagem (imagem estática, imagem em movimento, fala, música) que o cercam, ou intercalam ou impregnam; esses textos multissemióticos extrapolaram os limites dos ambientes digitais e invadiram também os impressos (jornais, revistas, livros didáticos). (ROJO, 2009, p. 105-106)

Ou seja, embora possamos contar, já na segunda década do século XXI, com inúmeros recursos disponibilizados pelas tecnologias digitais, os artigos científicos, divulgados nos periódicos cujo suporte é o digital, não se adequaram a essa nova 


\section{Revista do SELL}

v. $4, n^{\circ} .1$

ISSN: $1983-3873$

tecnologia, o que nos leva a questionar a até que ponto os pesquisadores estão interessados nas modificações estruturais viabilizadas pelas tecnologias digitais.

\section{Suporte impresso versus suporte digital}

Os artigos de divulgação científica publicados nas revistas/periódicos científicos são formas utilizadas para preservar o conhecimento neles publicados, pois além de servirem como meio de comunicação entre os pesquisadores, também são utilizados como meios para a divulgação dos resultados de pesquisa e para o estabelecimento de prioridade científica, sendo este último um consenso na comunidade acadêmica e científica.

Sendo um exemplo clássico da divulgação científica formal, trata-se de um meio de comunicação criado pelos cientistas para seus pares, assim, para que possamos melhor compreender o uso dos periódicos eletrônicos por seus criadores e usuários, buscamos fazer um estudo voltado para esse nicho. Neste sentido, para este estudo, nos baseamos nos estudos de Schauder (1994) e Kurata et al (2007).

Para Kurata et al (2007) a definição de "revista/periódico eletrônica" ainda não foi claramente estabelecida, pois por muito tempo o termo foi utilizado para nomear os periódicos eletrônicos, no entanto, na atualidade, são entendidos como as versões eletrônicas de periódicos impressos tradicionais. O que nos permite dizer que o conceito de periódico eletrônico ainda foi claramente estabelecido pela literatura, o que se sabe é que este conceito aponta para uma ferramenta muito parecida com a dos periódicos impressos, o que pode nos ajudar a elucidar as razões para o seu uso.

Os estudos de Kurata et al indicaram que os cientistas japoneses, de maneira geral, consideram o artigo científico como uma fonte primária das informações científicas. A mesma pesquisa indicou que os pesquisadores ainda preferem copiar os textos para que possam ter um exemplar próprio, tanto impresso como eletrônico. Outro dado significativo, que pudemos comprovar por meio de conversas informais com pesquisadores que estão realizando pesquisas de mestrado e doutorado - mesmo aqueles cujas pesquisas envolvem estudos relacionados às TDICS - ainda preferem imprimir os textos publicados em meio eletrônico a lerem-nos em tela. Para Kurata et al (2007, p. 1408) os arquivos HTML são muito pouco usados ao contrário do que acontece com os arquivos PDF, o que indica que mesmo sabendo que a referenciação feita por meio de hiperlinks seja uma forma mais acessível e facilita a leitura, os pesquisadores 


\section{Revista do SELL \\ v. $4, n^{\circ} .1$ \\ ISSN: $1983-3873$}

ainda optam pelas formas tradicionais de leitura baseadas nos textos lineares, mesmo quando utilizam os mídias digitais.

Já os estudos de Schauder (1994) nos mostram que os pesquisadores norte americanos, ingleses e australianos, ao escolherem as revistas para as quais vão submeter seus trabalhos e pesquisas, o fazem em razão do prestígio dos periódicos, e os mais importantes ainda optam pelo formato impresso dos textos, mesmo os eletrônicos. Assim, o que Schauder descobriu em relação aos hábitos de leitura e escrita dos pesquisadores ocidentais em 1994 foi também constatado pelos estudos de Kurata et al (2007), ou seja, a grande maioria dos cientistas, já no final da primeira década do século XXI, ainda optava pela impressão do artigo publicado em meio digital para lê-lo linearmente no papel.

O que a nossa pesquisa, ainda em andamento, com pesquisadores de mestrado e doutorado cujos estudos estão relacionados ao uso das TDICS sobre os seus hábitos de leitura e escrita, tem nos sinalizado, até o momento, é que esse comportamento permanece ainda hoje, por meio da transposição do texto para o arquivo PDF. Assim, a estrutura composicional e o estilo dos artigos científicos modernos, não obstante as inúmeras possibilidades oferecidas pelo meio digital como hiperlinks e hipermídias, continua linear. O que nos permite dizer que os hábitos dos produtores e leitores de artigos de divulgação científica da atualidade ainda permanecem atrelados à superestrutura dos textos impressos e que o conhecimento científico continua sendo produzido linearmente, para ser lido de forma linear seja no suporte impresso ou na tela do computador, uma vez que as tecnologias são utilizadas de forma semelhante.

Ao contrário dos textos produzidos para serem consumidos tanto na modalidade impressa quanto digital, o texto criado especificamente para o meio digital não pode ser impresso, por sua própria natureza ele é produzido levando-se em consideração as características próprias das hipermídias que não podem ser transpostas para a modalidade do meio impresso.

É importante ressaltar que o fato de um texto ser escrito com a utilização de um software de edição de texto não o torna um texto digital, pois a disposição desestruturada e não linear de sua estrutura e sua apresentação tem como característica principal a troca de informações, a interatividade e a colaboração entre escritores e leitores e entre computadores.

Neste sentido, os artigos científicos originalmente produzidos para o meio digital têm como característica fundante o fato de se utilizarem das possibilidades oferecidas 


\section{Revista do SELL \\ v. $4, n^{\circ} .1$ \\ ISSN: $1983-3873$}

pelo hipertexto e pela hipermídia visual, a navegação por abas, ou partes do texto que propicia uma leitura não linear; além da comunicação entre máquinas viabilizada pela Internet. Outro aspecto a ser considerado, conforme Seringhaus e Gerstein (2007) é a fusão entre revistas eletrônicas e as bases de dados, o que demonstra o comportamento que os pesquisadores têm diante dessas fontes.

Neste sentido, pode-se dizer que uma característica própria dos textos produzidos para o meio digital é a multissemiose e a multimodalidade, haja vista as inúmeras possibilidades que os mídia digitais oferecem para a produção de textos que mesclam sons, imagens, textos escritos, elementos pictóricos e imagéticos, todos dispostos de forma não linear, o que permite uma navegação pelo texto de acordo com os interesses do leitor, ou seja, a possibilidade de interação entre leitor e texto é maximizada. O leitor deixa de ser um consumidor passivo e passa a ter uma atitude responsiva frente ao texto que Ihe foi apresentado.

\section{Algumas considerações finais}

Partindo da teoria bakhtiniana sobre o gênero, observamos que os gêneros são formas de dizer, situadas e contextualizadas, existentes na sociedade. Essas formas de dizer e de criar sentidos - desenvolver temas - são cristalizadas historicamente pelo funcionamento de certos campos ou esferas sociais - no caso do artigo de divulgação científica, a esfera científica - que formatam e regularizam, mas de maneira flexível, temas que podem ser abordados, formas ou organizações dos textos esperados, estilos admitidos - variedades linguísticas, jargões etc.

Assim, o texto é flexível, pois se adapta às diversas situações de comunicação, ou seja, aos propósitos comunicativos do seu produtor, o que nos permite dizer que são legião, e, sendo tantos e tão diversos, exigem de seus produtores e leitores capacidades e habilidades relacionadas ao meio e à forma que pretendem dar aos seus textos.

Assim, considerando que estilo e forma composicional estão sempre a serviço do tema, apresentou-se neste breve ensaio, um recorte histórico sobre como as tecnologias foram se incorporando às nossas atividades acadêmicas; como o artigo científico tem sido estruturado ao longo da história, e algumas características relacionadas ao artigo acadêmico produzido para o meio digital.

Ressalta-se que este diálogo não deve ser desvinculado de uma teoria da prática social, da maneira como os atores sociais demonstram estrategicamente sua adesão aos 


\section{Revista do SELL \\ v. $4, n^{\circ} .1$ \\ ISSN: $1983-3873$}

valores de sua comunidade discursiva, do fato de que o texto apresenta-se a si mesmo como um discurso autorizado por atores sociais legitimados e específicos que vincula as unidades textuais a estruturas dominantes, e que essas exercem uma real influência sobre as formas e características por meio das quais os gêneros são realizados.

Outro aspecto a ser ressaltado é a questão da atualidade e da incompletude do gênero artigo científico, pois a realidade histórica é produzida a partir da avaliação social dos discursos e a sua prática, enquanto realidade inscrita no tempo, é sempre não acabada.

$\mathrm{Na}$ atualidade, contudo, os pesquisadores utilizam muito o meio digital para a divulgação de suas pesquisas por meio do artigo científico, no entanto, nem por isso, este texto apresenta-se no formato digital e sua estrutura permanece quase que inalterada ao longo de três séculos. A utilização do meio digital para publicação de artigos científicos propriamente digitais fará com que o nível de agência e responsividade do leitor seja aumentado sobremaneira, o que possibilitará maiores e melhores discussões acadêmicas em torno de um determinado objeto de estudo bem como a interatividade e colaboratividade - características primordiais e fundamentais dos novos mídia digitais entre produtor e leitor do gênero artigo científico.

Parece-nos que, em relação ao crescente número de estudos e pesquisas que, de uma forma ou de outra, estão relacionados ao advento das tecnologias digitais da informação e comunicação e seus usos, vive-se hoje o paradoxo do heterodoxo em busca pela ortodoxia.

\section{REFERÊNCIAS BIBLIOGRÁFICAS}

ARANHA, S. A busca de modelos retóricos mais apropriados para o ensino da escrita acadêmica. Revista do GEL (Araraquara), v. 4, p. 97-114, 2007.

BAKHTIN, M. Problemas da Poética de Dostoievski. RJ: Forense Universitária, 1981.

Os gêneros do discurso, in: BAKHTIN, M. M. Estética da criação verbal. São Paulo: Martins Fontes, 1997.

BUZATO, M. E. K. Entre a fronteira e a periferia: linguagem e letramento na inclusão digital. 2007, 284f. Tese (Doutorado em Linguística Aplicada) - IEL, Universidade Estadual de Campinas, Campinas/SP, 2007. 


\section{Revista do SELL}

v. $4, n^{\circ} .1$

ISSN: $1983-3873$

, Multiletramentos, Linguagens e Mídias. In: ROJO, R. H. R. (Coord.) Curso de Especialização em Língua Portuguesa On-line. $1^{\text {a }}$ ed. REDEFOR - IEL/UNICAMP - SEESP, 2011.

GILSTER, P. Digital literacies. NC State University, Raleigh, NC: John Wiley and Sons, 1997.

KALANTZIS, M. e COPE, B. Designs for social future. In: B. COPE; M. KALANTZIS (orgs). Multiliteracies - literacy learning and the design of social futures. New York: Routledge, 2006

KURATA et al. Electronic journals and their unbundled functions in scholarly communication: views and utilization by scientific, technological and medical researchers in Japan. Information Processing and Management, v. 43, 2007, p. 1402-1415.

LEMKE, J. L. Metamidia literacy: transforming meanings and media, in: REINKING, D. et alii (orgs). Handbook of literacy and technology: transformations in a post-typographic world. Hillsdate: Erlbaum, 1998.

MARCONI, M. A.; LAKATOS, E. M. Técnicas de pesquisa. Brasil: Atlas, 1982.

McKIE, D. The Scientific Periodicals from 1665 to 1789. In: MEADOWS, A.J., ed. The Scientific Journal. London, ASLIB, 1979.

MITCHELL, D. The End of Public Space? People's Park, Definitions of the Public, and Democracy. Annals of the Association of American Geographers. V. 85, 1를. Ep. $108-$ 133, Março de 1995. Disponível em: http://onlinelibrary.wiley.com/doi/10.1111/j.14678306.1995.tb01797.x/abstract Acesso em: 20/11/2012.

ROJO, R. Letramentos múltiplos, escola e inclusão social. São Paulo: Parábola, 2009.

Protótipos didáticos para os multiletramentos. In: ROJO, R. e MOURA, E. (orgs) Multiletramentos na Escola. São Paulo: Parábola Editorial, 2012.

SCHAUDER, Don. Electronic publishing of Professional articles: attitudes of academics and implications for the scholarly communication industry. Journal of the American Society for Information Science, v. 45, n. 2, p. 73-100, Mar. 1994. 


\section{Revista do SELL \\ v. $4, n^{\circ} .1$ \\ ISSN: 1983-3873}

SERINGHAUS, Michael; GERSTEIN, Mark B . Publishing perishing? Towards tomorrow's information architecture. BMC Bioinformatics, v. 8, n. 17, Jan. 2007

SWALES, J. M. Genre analysis: English in academic and research settings. Cambridge: Cambridge University Press, 1990.

; FEAK, C. B. Academic writing for graduate students: essential tasks and skills. Michigan: The Uniersity of Michigan Press, 1994.

VAN DIJK, T. A. La ciência del texto: um enfoque interdiciplinario. Buenos Aires/Barcelona: Paidós, 1987. 